\title{
Spermatotoxic effect of aflatoxin B1 in rat: extrusion of outer dense fibres and associated axonemal microtubule doublets of sperm flagellum
}

\author{
K Faisal, V S Periasamy, S Sahabudeen ${ }^{1}$, A Radha, R Anandhi and M A Akbarsha \\ Department of Animal Science, School of Life Sciences, Bharathidasan University, Tiruchirappalli 620 024, India \\ ${ }^{1}$ Department of Biotechnology, SRM University, Kancheepuram 603 203, India
}

Correspondence should be addressed to M A Akbarsha; Email: akbarbdu@yahoo.com

\begin{abstract}
Male Wistar rats were treated with aflatoxin B1 (AFB1). Live as well as methanol-fixed cauda epididymal spermatozoa were stained with acridine orange (AO) and ethidium bromide (EB) and observed under a fluorescence microscope. Giemsa-stained smears were observed in a bright field microscope. Unstained smears were observed with phase contrast illumination. The axoneme of more than $10 \%$ of the spermatozoa of treated rats had the outer dense fibres (ODFs), in varying numbers, and the associated axonemal microtubule doublets of the flagellum extruded either at midpiece-principal piece junction or connecting piece. This could be perceived in all light microscopic preparations, but AO-EB staining offered an advantage of the assessment of the viability as well. TEM observation of sections of the testis and cauda epididymidis also revealed ODF extrusion, as seen in the transverse sections of sperm flagella missing one or more ODFs and the associated axonemal microtubule doublets. In a few such sections, the extruded elements were seen in the cytoplasm, outside the mitochondrial sheath or peripheral sheath. Marginal to severe mitochondrial pathologies were observed in the spermatozoa and elongated spermatids, suggesting a link between AFB1-induced sperm mitochondrial pathology and extrusion of ODFs. However, the possibility that AFB1 treatment would disrupt the cytoskeletal proteins of the flagellum, resulting in the extrusion of ODFs, cannot be excluded. This sperm abnormality is reported for the first time as produced by a dietary toxin. Dietary aflatoxins, therefore, could also be contributory factors for the deterioration of the reproductive health of men.
\end{abstract}

Reproduction (2008) 135 303-310

\section{Introduction}

There has been serious concern in the recent past regarding the deterioration of human and animal male reproductive health (Carlsen et al. 1992, 1993, Sharpe 1992, Sharpe \& Skakkebaek 1993, Veeramachaneni 2000, Handelsman 2001). The contributory factors for this deterioration have been traced to environmental, industrial and occupational chemicals, therapeutics, dietary toxins, lifestyle factors, etc. (Skakkebaek et al. 1998, Herath et al. 2004, Aruldhas et al. 2006, Slama et al. 2006, Winters et al. 2006). Some of the manifestations of this deterioration include oligozoospermia, azoospermia, teratozoospermia, asthenozoospermia and oligoteratoasthenozoospermia. In these cases there is a defective spermatogenesis at the level of the testis and/or incomplete epididymal processing of spermatozoa (Yanagimachi 2005, Sharpe 2006). Such spermatozoa are abnormal in morphology and/or motility, which are pathophysiological attributes, and the ejaculates contain these sperm in varying abundance (Sharpe 2006). This affects not only in vivo reproduction in animals and men but also the outcomes of in vitro fertilization as well as intracytoplasmic sperm injection. A few reports have shown that such pathological spermatozoa are acquired by the epididymal epithelial cells and processed, suggesting a newer role to epididymal epithelial cells (Seiler et al. 2000, Sutovsky et al. 2001a, 2001b, Holschbach \& Cooper 2002, Aruldhas et al. 2006).

Aflatoxins are toxic metabolites of Aspergillus flavus and Aspergillus parasiticus and are naturally occurring contaminants of food. Aflatoxin poisoning is a recurrent public health problem. More than 5 billion people in developing countries worldwide are at risk of chronic exposure to naturally occurring aflatoxins, aflatoxin B1 (AFB1), AFB2, AFG1 and AFG2, through contaminated foods (Shephard 2003, Williams et al. 2004) and more so in the tropical regions, where people rely on commodities such as cereals, oilseeds, spices, tree nuts, milk, meat and dried fruits that are potentially contaminated by aflatoxins (Strosnider et al. 2006). Aflatoxins can produce serious health effects including carcinogenesis (Williams et al. 2004, Preston \& Williams 2005, Abnet 
2007), mutagenesis (Wang and Groopman 1999, Peters \& Teel 2003), growth retardation (Gong et al. 2002, 2003, 2004, Williams et al. 2004) and immune suppression (Turner et al. 2003, Williams et al. 2004). Although a great deal is known about aflatoxins, little is known about aflatoxin exposure and the resulting health effects in developing countries (Strosnider et al. 2006). Thus, though male reproductive toxic effects of aflatoxins in humans have not yet been investigated, such an effect cannot be eliminated in the light of reports coming from domestic and experimental animals (Faridha et al. 2007 and the references therein) and also from a human study correlating aflatoxin content of semen and semen parameters of infertile men (Uriah et al. 2001).

Our laboratory has been concerned with male reproductive toxicological evaluation for several years and we found disruption of spermatogenesis (Faridha et al. 2006, 2007) and production of defective spermatozoa (Agnes \& Akbarsha 2001, 2003) when Swiss mice were treated with AFB1, the most potent and potentially lethal metabolite. Susceptibility to aflatoxins can differ between test animals (Bennett \& Clich 2003). Therefore, in order to find if the male reproductive toxic effect of AFB1 would differ between species, and if pathophysiological spermatozoa thus produced are ubiquitinated for acquisition by epididymal epithelial principal cells (Seiler et al. 2000, Sutovsky et al. 2001a, 2001 b, Holschbach \& Cooper 2002, Aruldhas et al. 2006), we repeated the investigation in the Wistar rats. We practiced a single dose $(20 \mu \mathrm{g} / \mathrm{kg}$ body weight) at one time point based on the standardization done in our earlier work (Agnes \& Akbarsha 2001, 2003, Faridha et al. 2006, 2007). We found several sperm abnormalities, and most spermatozoa were not motile, as was the case in the mouse (Agnes \& Akbarsha 2001, 2003). In addition, we found evidence for the extrusion of outer dense fibres (ODFs) along with the associated axonemal microtubule doublets from the flagella of more than $10 \%$ of the sperm, either at the connecting piece or at the mid-piece-principal piece junction. Though this abnormality has been reported as caused by a few other etiological factors, this is the first report to suggest that it is due to treatment with a dietary toxin. Transmission electron microscopy (TEM) evidence points to a link between this sperm pathology and mitochondrial defects, although disruption of cytoskeletal polymeric proteins cannot be excluded.

\section{Results}

Unlike the control rats, in which $95 \pm 5 \%$ of the sperm had normal morphology (Fig. 1A) and $94 \pm 4 \%$ (concentration $62 \pm 6 \times 10^{6} / \mathrm{ml}$ of the diluted cauda epididymidal fluid) made forward progressive motility for an hour and more, in the AFB1-treated rats, as observed in bright field, dark field and/or phase contrast illumination, the sperm concentration was significantly lower $\left(20 \pm 4 \times 10^{6} / \mathrm{ml}\right.$ of the diluted cauda epididymidal fluid) and $63 \pm 8 \%$ of these sperm had morphological abnormalities. The most predominant sperm abnormality was detachment of head from the flagellum $(32 \pm 9 \%$ in the treated, as against $3 \pm 1 \%$ in the control; Fig. 1B). Red fluorescence of the detached heads indicated these, and several intact spermatozoa, as not viable. In addition, more than $11 \pm 1 \%$ of spermatozoa exhibited abrupt narrowing of the flagellum at the midpiece-principal piece junction and subsequent extrusion of ODFs and the associated axonemal microtubule doublets at these narrow regions, which we did not observe in any of the spermatozoa of control rats. In the earliest appearance, this region measured 1-2 $\mu \mathrm{m}$ long (Fig. 1C and G) but could measure up to 9-10 $\mu \mathrm{m}$ (Fig. 1D-F and $\mathrm{H}-\mathrm{O}$ ). The ODFs and the associated axonemal microtubule doublets were extruded from this region in the form of one or more arches, each to various degrees (Fig. 1G-X). These spermatozoa did not exhibit forward progressive motility but a few exhibited sideways lashing of the flagellum at the very early stages but, subsequently, the lashing stopped. At more advanced stages, the entire fibrous sheath $(\mathrm{FS})$ at the mid-piece-principal piece junction was flexed to one side such that all the ODFs and the associated axonemal microtubule doublets flayed out (Fig. 1V). These manifestations were also present in spermatozoa, which were fused in various numbers and to various lengths (Fig. 1S).

The connecting piece also had this manifestation and, ultimately, ended up with one or more ODFs and the associated microtubule doublets of the axoneme extruding as individual fibres (Fig. 2A-F). The observations made of the methanol-fixed sperm stained with Giemsa and unstained sperm viewed with phase contrast illumination were the same as above (not shown).

TEM analysis of spermatozoa in transverse sections through the mid-piece or principal piece revealed that several of them were missing one or more ODFs and the associated axonemal microtubule doublets (Fig. 3A-D). In a few sections of the principal piece, the ODFaxonemal microtubule doublet complexes were seen between the FS and plasma membrane (Fig. 3D). In the spermatozoa with normal flagella, the mitochondrial sheath (MS) was intact (Fig. 4A). On the other hand, the MS under formation of several elongated spermatids in the seminiferous tubules (Fig. 4B) and the cauda epididymidal luminal spermatozoa (Fig. 4C) of AFB1treated rats indicated pathological changes of different kinds, the most prevalent being swelling of several mitochondria and their missing, irregular or discontinuous spacing. In the normal spermatozoa, the connecting piece (Fig. 5A) as well as midpiece-principal piece junction (annulus; Fig. 5C) had the respective characteristic organizations. However, in several abnormal elongated spermatids and differentiated spermatozoa, the MS ended abruptly either subjacent to the connecting 

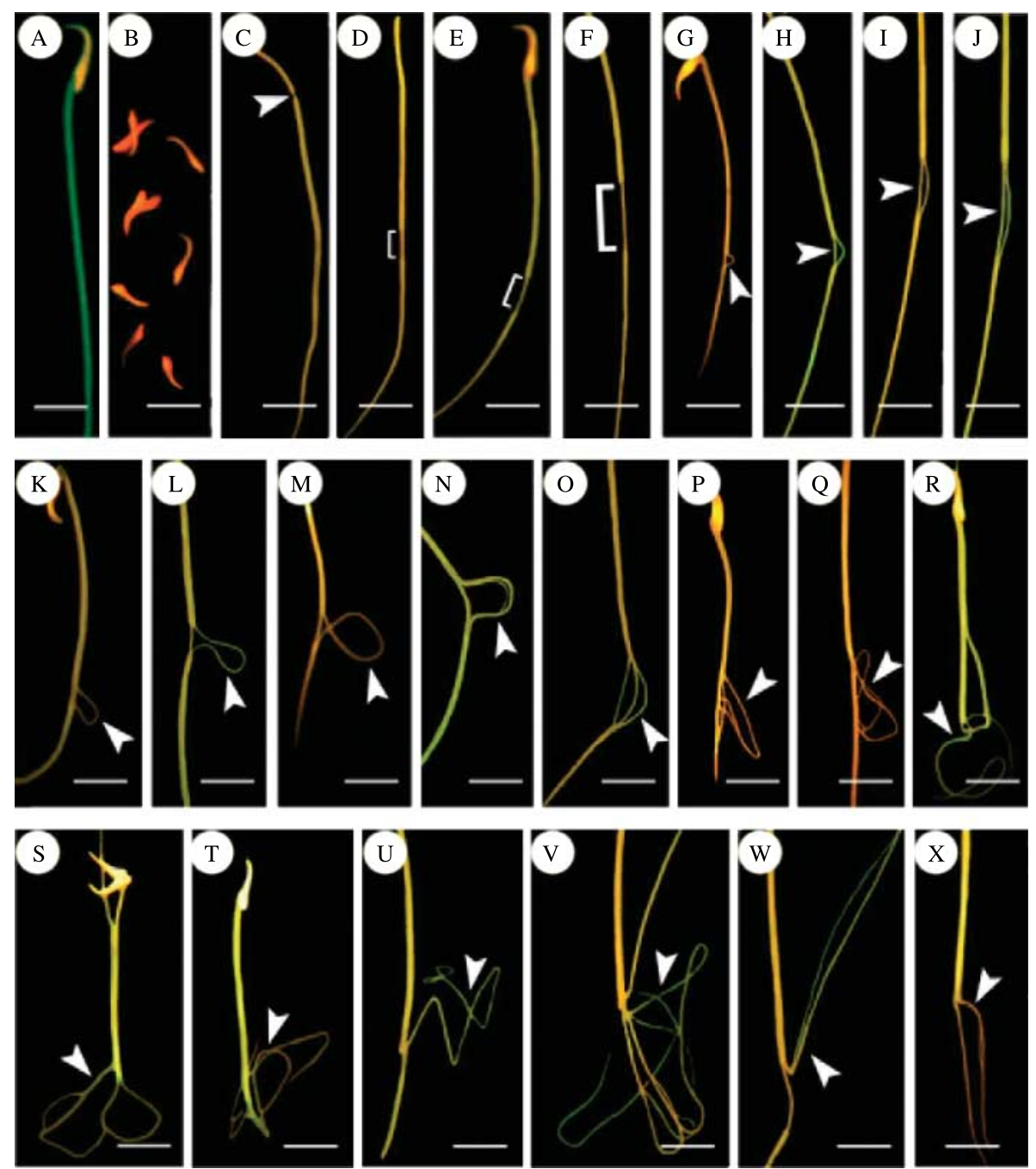

Figure 1 AO-EB stained spermatozoa of AFB1-treated rat observed in a fluorescence microscope. (A) A normal viable sperm; (B) detached heads, non-viable; (C)-(F) spermatozoa showing a narrow region at the mid-piece-principal piece junction (indicated by an arrowhead or square bracket); (G-X) extrusion of one or more ODFs and the associated axonemal microtubule doublets to varying degrees (arrowheads; note the extrusion of ODFs from the flagella of fused spermatozoa in $\mathrm{S}$, and sideways flexing of the peripheral sheath, exposing all ODFs and the associated axonemal microtubule doublets, in V). Scale bar: $15 \mu \mathrm{m}$.

piece (Fig. 5B) or ahead of the midpiece-principal piece junction (Fig. 5D), resulting in a short length of axoneme at these critical positions, from where the ODF-axonemal microtubule doublets would extrude. Further, while there was dense accumulation around the striated columns and capitulum of the connecting piece, in several steps 15-19 spermatids were not properly developed (Fig. 5A and B).

\section{Discussion}

Aflatoxins are among the serious food contaminants (Williams et al. 2004, Strosnider et al. 2006) and disruptors of male reproductive structure and function through the dietary route (Egbunike et al. 1980, Sharlin et al. 1980, Egbunike 1982, Hafez et al. 1982, lbeh et al. 1994, Ibeh \& Saxena 1998, Agnes \& Akbarsha 2001,
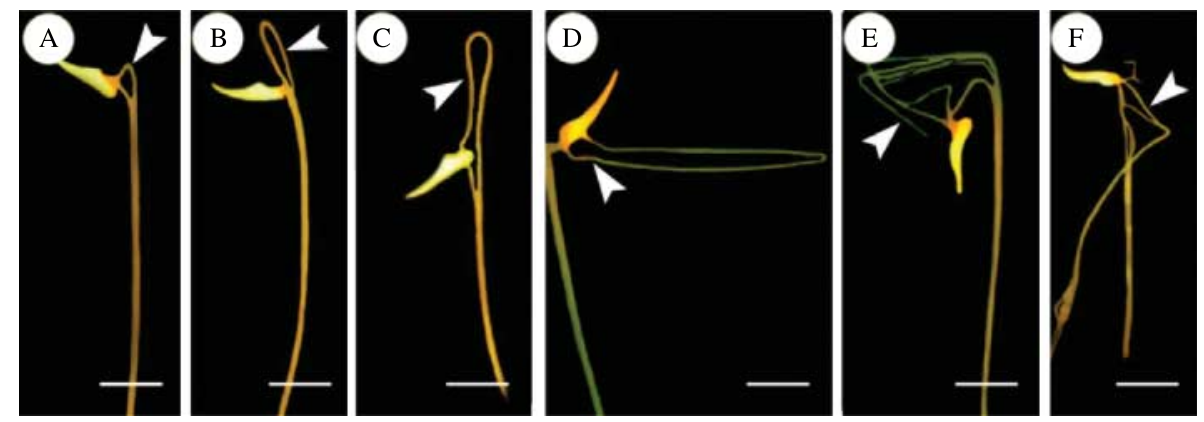

Figure 2 AO-EB-stained spermatozoa of AFB1-treated rat observed in a fluorescence microscope, showing extrusion of one or more ODFs and the associated axonemal microtubule doublets, to varying degrees, at the connecting piece (arrowheads). Scale bar: $15 \mu \mathrm{m}$. 

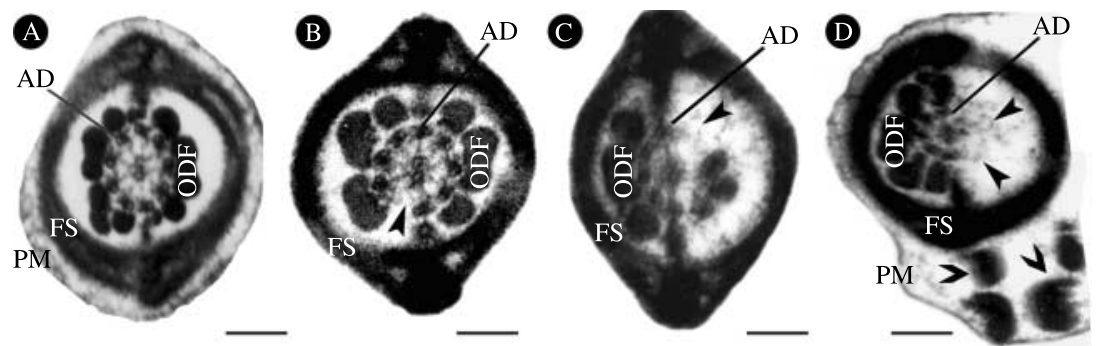

Figure 3 TEM of transverse sections of principal piece of spermatozoa of AFB1-treated rats. (A) Normal organization; (B) slight disruption of the axoneme and ODF; (C) one axoneme and the associated axonemal doublet are missing (arrowhead); (D) ODFs and associated microtubule doublets on one side are missing (arrowheads) and are seen in the cytoplasm between the fibrous sheath and sperm membrane (wide arrows). AD, axonemal doublet; FS, fibrous sheath; PM, sperm membrane; ODF, outer dense fibres. Scale bar: $0.24 \mu \mathrm{m}$.

2003, Faridha et al. 2006, 2007). Focused studies on the spermatotoxic effect of aflatoxins in animal models have revealed that the exposure would affect the morphology as well as physiology of spermatozoa (Hafez et al. 1982, Agnes \& Akbarsha 2003). The various sperm abnormalities reported in AFB1-treated mice consisted of head without the hook, several unusual shapes, vacuolation of the head, incomplete head, bent or coiled tail, detachment of the head from flagellum, fusion of flagella of two or more sperm over short to long distances and retention of cytoplasmic droplets (Agnes \& Akbarsha 2003). This paper reports, in addition, extrusion of one or more ODFs along with the respective microtubule doublets of the axoneme at the mid-piece-principal piece junction and/or connecting piece of rat sperm.

Aflatoxins or their metabolites can reach the testis (Bukovjan et al. 1992) and be present in the semen through this route (Picha et al. 1986, Ibeh et al. 1994, Uriah et al. 2001). Infertile men with high concentrations of aflatoxins in semen had decreased sperm counts and increased incidence of sperm abnormalities (Uriah et al. 2001). Thus, there is an imminent link between chronic exposure of men to aflatoxins and male reproductive health. Therefore, generating data from human studies in this regard and understanding the manifestations and the mechanisms of action from animal studies are highly relevant in the light of poor understanding of the health effects of aflatoxins (Strosnider et al. 2006). Thus, this study contributes to the understanding of the male reproductive health effects of aflatoxins, particularly the manifestations in the affected sperm.

A thorough screening of literature revealed that this kind of sperm abnormality has been reported only in very few instances. Olson \& Linck (1977) reported extrusion of axonemes from demembranated rat spermatozoa in the presence of ATP. Cooper \& Hamilton (1977) found that in several spermatozoa caught in a dense material occurring in patches in the lumen of epididymis and vas deferens, the MS was no longer intact and there was complete disruption and dissolution of the ODFs and axonemes. Olson et al. (2004) found similar abnormal spermatozoa produced in selenium-deficient rats. In these spermatozoa, the MS terminated prematurely, producing gaps in the most proximal region of the MS accompanied by separation and/or extrusion of the underlying fibrils of the ODFaxonemal microtubule doublet complex. The extrusion of flagellar fibres was noticed in the connecting piece also. Olson et al. (2005) generated selenoprotein $\mathrm{P}$ (SEPP1)-null male mice, which also produced sperm of this kind. Andersen et al. (2003) found sperm with morphological abnormalities produced in apoER-2 deficient mice. Several sperm produced by these mice had defects comparable to those in the present report (TG Cooper, personal communication). Thus, relying on
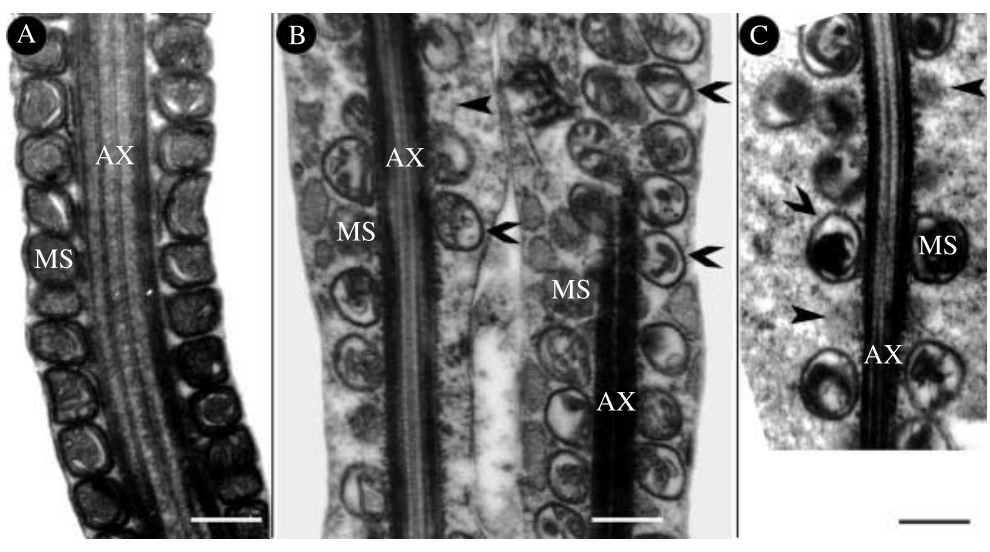

Reproduction (2008) 135 303-310
Figure 4 TEM of longitudinal sections of the middle piece of spermatozoa of AFB1-treated rats. (A) Normal sperm from the cauda epididymidis showing intact and organized mitochondrial sheath; (B and C) two adjacent elongated spermatids in the seminiferous epithelium showing swelling (wide arrows) and aberrant spacing (arrowheads) of mitochondria in the mitochondrial sheath. AX, axoneme; MS, mitochondrial sheath. Scale bar: $0.33 \mu \mathrm{m}$. 

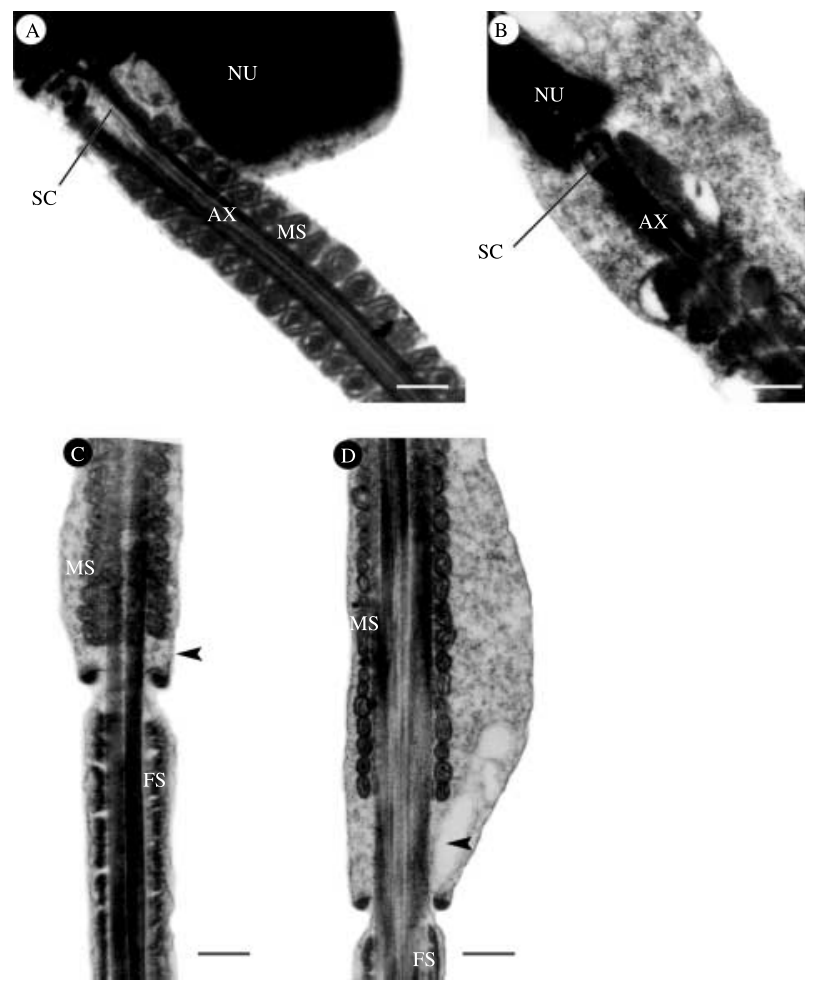

Figure 5 TEM of longitudinal sections of spermatozoa of AFB1-treated rats. (A) Normal cauda epididymidal sperm showing highly organized connecting piece; (B) defective elongated spermatid in the seminiferous epithelium showing abrupt ending of the mitochondrial sheath with vacuolated mitochondria and disruption of the dense material around the striated columns (arrowhead); (C) midpiece-principal piece junction of a normal sperm showing the annulus (arrowhead) and the complete mitochondrial sheath (arrow); (D) A defective sperm in which the mitochondrial sheath has ended abruptly ahead of the annulus (arrowhead) such that the axoneme is not wrapped around by the mitochondrial sheath (arrow), at the annulus, outside the axoneme. AX, axoneme; FS, fibrous sheath; MS, mitochondrial sheath; $\mathrm{NU}$, nucleus; SC, striated columns. Scale bar (A and B): $0.43 \mu \mathrm{m}$; (C and D): $0.40 \mu \mathrm{m}$.

the interpretation of Olson et al. $(2004,2005)$ and our TEM observations in respect of the pathological features of the MS, we presume that this flagellar defect could be related with abnormal development of the MS during spermiogenesis. The evidence further suggests that the AFB1-induced flagellar defect has a testicular origin as in the case of selenium-deficient rat (Olson et al. 2004) and SEPP1-null mice (Olson et al. 2005). Interestingly, the nutrition of both zinc and selenium is affected by aflatoxins in the diet (Kalorey et al. 1996, Mocchegiani et al. 1996). Thus, selenium deficiency caused due to AFB1 could be one of the possible mechanisms in generating this kind of abnormal spermatozoa, a point worth investigating. The other possibility is that aflatoxin-induced defect in the late maturation phase in the spermiogenesis results in a missing segment (gap) of the MS as has been observed in the spermatozoa of rat treated with gossypol (Hoffer 1982, Oko \& Hrudka 1982, Xue et al. 1983, Agarwal 1989, Barth \& Oko 1989, Bhiwgade \& Nair 1989, Swan et al. 1990).
The affected spermatozoa travel through the epididymis with structural weakness in the sheath leading to protrusion of axial fibres at this level, accompanied by retraction of the fibres from the parts of the tail below the gap (Oko \& Hrudka 1982). In this case, the problem is with the MS which is apparently affected by gossypol (Barth \& Oko 1989) or aflatoxin treatment (present study). Both gossypol and aflatoxin possess a phenolic ring in their chemical structures and this could be the basis of the induction of defects in the mitochondria by uncoupling oxidative phosphorylation, eventually causing the spermatid mitochondria to swell (Tso \& Lee 1982).

However, an effect on the cytoskeletal structures of the motility apparatus of sperm should also be considered seriously. Si \& Okuno (1993) treated activated mouse spermatozoa with Triton X-100 and dithiothreitol to remove the plasma membrane and MS of sperm flagella. When the mitochondria-free demembranated flagella were perfused with Mg-ATP and trypsin, the microtubule doublet of the axoneme and the FS were pulled proximally to the principal piece from the annulus. This FS sliding and the order of doublet ODF extrusion were trypsin concentration dependent ( $\mathrm{Si}$ \& Okuno 1995). Kinukawa et al. (2004) found microtubule extrusion in demembranated sperm of hamster and mouse treated with huge concentrations of protease inhibitor and dithiothreitol or 2-mercaptoethanol (2-ME). Sperm microtubule extrusion was also reported in elastase-treated human spermatozoa (Ishijima et al. 2002) and Triton X-100-treated bovine spermatozoa (Kanous et al. 1993). These studies linked microtubule extrusion to protease digestion. Aflatoxins can adduct with albumin and other proteins (Dash et al. 2007). This adduction can affect the protein structure and function. The structural integrity and normal functioning of sperm depend greatly on the several cytoskeletal proteins such as actin, tubulin, vimentin, tektin, septin, spectrin, ankyrin, etc. of flagella (Irons 1983, Kann et al. 1993, 1998, Paranko et al. 1994, Schalles et al. 1998, Inaba 2003, Ihara et al. 2005, lida et al. 2006, Azamar et al. 2007, Roy et al. 2007, Touré et al. 2007, Vaid et al. 2007, Xiao \& Yang 2007). Aflatoxins are potential culprits of disrupting cytoskeletal protein dynamics (Koo et al. 1987, Wirth 1994, Albertini et al. 1988). There is indirect evidence for the disruption of actin microfilaments at the cytoplasmic bridges connecting male germ cell clones in the mouse (Faridha et al. 2007).

In making this observation, we adopted several light microscopic techniques in addition to TEM. The application of AO-EB staining has the advantage of revealing not only the morphological abnormalities but also the sperm viability. This technique has been applied for the spermatozoa in two earlier studies, Le Lannou \& Blanchard (1988) and Sivashanmugam \& Rajalakshmi (1997), though not for the detection of sperm abnormalities and viability. 
The cause for the loss of viability of spermatozoa of AFB1-treated rat is another area worthy of investigation. The morphological abnormalities, including breaking away of the head from flagellum and extrusion of ODFs and associated axonemal doublets, could be one of the immediate causes. However, the AO-EB staining pattern of sperm nuclei indicates DNA strand breaks, as revealed in the AO staining, as well as the loss of membrane integrity and chromatin condensation, as revealed in the EB staining, and suggests targets including DNA. Aflatoxins can adduct with the DNA of the testis and, thus, bring about DNA damage of germ cells (Sotomayor et al. 1999).

Thus, our paper reports extrusion of one or more ODFs and the associated microtubule doublets of the axoneme of spermatozoa of AFB1-treated rats at the midpieceprincipal piece junction and/or connecting piece; aflatoxin therefore could be a potential risk factor affecting reproductive health in men in developing countries chronically exposed to aflatoxins through the dietary route.

\section{Materials and Methods}

Institutional Animal Ethics Committee (IAEC), established under the auspices of Committee for Purpose of Control and Supervision of Experiments on Animals (CPCSEA), Government of India, approved the experiment. Ninety-day-old Wistar strain male rats, raised from a stock obtained from the Indian Institute of Science, Bangalore, India, were used. AFB1 was obtained from Sigma Chemical Company and was dissolved in olive oil at $20 \mu \mathrm{g} / \mathrm{ml}$ concentration. The toxin was injected into ten rats (three months old) through i.m. route at a daily dose of $20 \mu \mathrm{g} / \mathrm{kg}$ body weight i.e. $0.2-0.25 \mathrm{ml} /$ day, depending on the weight of the animal (Agnes \& Akbarsha 2001, 2003) for 55 days, the duration of one spermatogenic cycle (Clermont 1962, Hess 1990) and the control animals in equal number received the oil alone. At the end of the treatment, five rats in each group were subjected to cervical dislocation and dissected to expose the testicles and epididymides. After a thorough wash in normal saline, $0.5 \mu \mathrm{l}$ fluid from the cauda epididymidis was collected in a cannula and diluted with $99.5 \mu \mathrm{l} \mathrm{PBS}, \mathrm{pH} 7.4$, according to Akbarsha et al. (2000). The sperm numbers were assessed with a Neubauer counting chamber and expressed as number per $\mathrm{ml}$ of the original cauda epididymidal fluid. The duration and extent of motility of the diluted spermatozoa were assessed in a hanging drop preparation observed in phase contrast and/or dark field illumination in a Carl Zeiss Axioscope 2 Plus research microscope (Jena, Germany) at $\times 400$ magnification. Giemsastained smears were observed in bright light at $\times 400$ or $\times 1000$. Unstained fresh sperm smears were observed in phase contrast illumination at $\times 400$.

In order to find the viability of spermatozoa, fresh sperm were stained with acridine orange (AO) and ethidium bromide (EB), according to Spector et al. (1997). To a glass slide, $50 \mu \mathrm{l}$ dilute semen was transferred using a micropipette and $10 \mu \mathrm{l}$ each of $\mathrm{AO}$ (Sigma; $100 \mu \mathrm{g} / \mathrm{ml}$ in normal saline, $\mathrm{pH}$ 7.4) and EB (Bio-Rad; $100 \mu \mathrm{g} / \mathrm{ml}$ in normal saline, $\mathrm{pH}$ 7.4) were added separately, according to Spector et al. (1997). A cover slip was placed on the drop and the edges were sealed with fingernail polish. Then the smears of sperm, fixed in methanol, were also stained. The preparations were observed in the same microscope, now with epifluorescent attachment. In all cases the images were captured in a Pentium III computer via a Sony DXC-151AP CCD camera (Tokyo, Japan) using Carl-Zeiss Axiovision image-analysis software. In all cases of counts of spermatozoa with morphological abnormalities, 200 randomly selected spermatozoa from each slide were observed and assigned to the categories viz., normal, head alone and flagellar defect of interest in this study (Mortimer \& Mortimer 2005). The data were expressed as per cent of the total and used to calculate the mean \pm s.D.

Thin sections of the testis and cauda epididymidis, collected from the remaining control and treated rats (five each) perfused with Karnovsky's (1965) fluid, were fixed in glutaraldehyde and post-fixed in osmium tetroxide (Hess \& Thurston 1977). After a thorough wash in buffer (Hayat 1981), the sections were dehydrated in ethanol and cleared in propylene oxide. Infiltration was carried out in propylene oxide and Spurr's mixture (Sigma Chemical Co). The tissues were embedded in Spurr's mixture and semithin sections $(1 \mu \mathrm{m}$ thickness) were stained with toluidine blue-O (TBO) for selecting the areas for ultrathin sections. The latter were obtained in a Leica ultramicrotome (Jena, Germany) and stained in Reynold's lead citrate and $6 \%$ aqueous uranyl acetate. The sections were examined and those of elongated spermatids from the testis and spermatozoa from the cauda epididymidis were photographed with a transmission electron microscope (Phillips 201C; Phillips, Amsterdam, The Netherlands). The TEM images were scanned into the computer and the images, in all cases, were processed with Adobe Photoshop 7.0 software to clean the background and adjust the brightness and contrast.

\section{Acknowledgements}

The study was supported by a grant from the Department of Science and Technology (DST), Government of India, New Delhi, to M A Akbarsha (no. SR/SO/AS-59/2004). The instrumentation facility under the FIST scheme of DST (no. SR/FST/LSI-112/2002) and the grant under Special Assistance Programme (SAP) of University Grants Commission (UGC), Government of India, New Delhi (no. F.3-5/2007 (SAP-II)) to the Department of Animal Science, Bharathidasan University, are gratefully acknowledged. We thank Wellcome Trust Research Laboratory, Christian Medical College and Hospital $(\mathrm{CMC} \& \mathrm{H})$, Vellore, for help in the TEM studies. The authors declare that there is no conflict of interest that would prejudice the impartiality of this scientific work.

\section{References}

Abnet CC 2007 Carcinogenic food contaminants. Cancer Investigation 25 189-196.

Agarwal A 1989 Antifertility and ultrastructural effects of optical isomers of gossypol administered intratesticularly in rats. Acta Europaea Fertilitatis 20 379-386.

Agnes VF \& Akbarsha MA 2001 Pale vacuolated epithelial cells in epididymis of aflatoxin-treated mice. Reproduction 122 629-641. 
Agnes VF \& Akbarsha MA 2003 Spermatotoxic effect of aflatoxin B(1) in albino mouse. Food and Chemical Toxicology 41 119-130.

Akbarsha MA, Latha PN \& Murugaian P 2000 Retention of cytoplasmic droplet by rat cauda epididymal spermatozoa after treatment with cytotoxic agents. Journal of Reproduction and Fertility 120 385-390.

Albertini S, Friederich U, Holderegger C \& Würgler FE 1988 The in vitro porcine brain tubulin assembly assy: effects of a genotoxic carninogen (aflatoxin B1), eight tumor promoters and nine miscellaneous substances. Mutation Research 201 283-292.

Andersen $\mathrm{OM}$, Yeung $\mathrm{CH}$, Vorum $\mathrm{H}$, Wellner $\mathrm{M}$, Andreassen TK, Erdmann B, Mueller EC, Herz J, Otto A, Cooper TG et al. 2003 Essential role of the apolipoprotein E receptor-2 in sperm development. Journal of Biological Chemistry 278 22989-23995.

Aruldhas MM, Subramanian S, Sekhar P, Vengatesh G, Govindarajulu P \& Akbarsha MA 2006 In vivo spermatotoxic effect of chromium as reflected in the epididymal epithelial principal cells, basal cells, and intraepithelial macrophages of a nonhuman primate (Macaca radiata Geoffroy). Fertility and Sterility 86 1097-1105.

Azamar Y, Uribe S \& Mújica A 2007 F-actin involvement in guinea pig sperm motility. Molecular Reproduction and Development $\mathbf{7 4}$ 312-320.

Barth AD \& Oko RJ 1989 Photomicrographic features of bovine sperm cell abnormalities. In Abnormal Morphology of Bovine Spermatozoaa, edn 1, pp 89-129. Ames, IA: lowa State University Press.

Bennett JW \& Klich M 2003 Mycotoxins. Clinical Microbiology Reviews 16 497-516.

Bhiwgade DA \& Nair IN 1989 Ultrastructural and biochemical changes in epididymis and vas deferens of gossypol treated rats. Indian Journal of Experimental Biology 27 510-518.

Bukovjan K, Hallmannová A, Karpenko A \& Prosek J 1992 Detection of aflatoxin B1 in tissues of free-living game animals (Lepus europaeus Phasisnus colchicus, Capreolus capreolus, Anas platyrhynchos). Zentralblatt für Veterinärmedizin Reihe B 39 695-708.

Carlsen E, Giwercman A, Keiding S \& Skakkebaek NE 1992 Evidence for decreasing quality of semen during the past 50 years. BMJ 305 609-613.

Carlsen E, Giwercman A, Skakkebaek NE \& Keiding N 1993 Decreasing quality of semen. BMJ 306461.

Clermont Y 1962 Quantitative analysis of spermatogenesis of the rat: a revised model for the renewal of spermatogonia. American Journal of Anatomy 111 111-129.

Cooper TG \& Hamilton DW 1977 Observations on destruction of spermatozoa in the cauda epididymidis and proximal vas deferens of non-seasonal male mammals. American Journal of Anatomy 149 93-110.

Dash B, Afrivie-gyawu E, Huebner HJ, Porter W, Wang JS, Jolly PE \& Ogukuos TD 2007 Determinants of the variability of aflatoxin-albumin adduct levels in Ghanaians. Journal of Toxicology and Environmental Health. Part A 70 58-66.

Egbunike GN 1982 Steroidogenic and spermatogenic potentials of the male rat after acute treatment with aflatoxin B1. Andrologia 14 440-446.

Egbunike GN, Emerole GO, Aire TA \& Ikegwuonu FI 1980 Sperm production rates, sperm physiology and fertility in rats chronically treated with sublethal doses of aflatoxin B1. Andrologia 12 467-475.

Faridha A, Faisal K \& Akbarsha MA 2006 Duration-dependent histopathological and histometric changes in the testes of aflatoxin B1-treated mice. Journal of Endocrinology and Reproduction 10 117-133.

Faridha A, Faisal K \& Akbarsha MA 2007 Aflatoxin treatment brings about generation of multinucleate giant spermatids (symplasts) through opening of cytoplasmic bridges: light and transmission electron microscopic study in Swiss mouse. Reproductive Toxicology 24 403-408.

Gong YY, Cardwell K, Hounsa A, Egal S, Turner PC, Hall AJ \& Wild CP 2002 Dietary aflatoxin exposure and impaired growth in young children from Benin and Togo: cross sectional study. BMJ 325 556-562.

Gong YY, Egal S, Hounsa A, Turner PC, Hall AJ, Cardwell KF \& Wild CP 2003 Determinants of aflatoxin exporsure in young children from Benin and Togo, West Africa: the critical role of weaning. International Journal of Epidemiology 32 556-562.

Gong Y, Hounsa A, Egal S, Turner PC, Sutcliffe AE, Hall AJ, Cardwell K \& Wild CP 2004 Postweaning exposure to aflatoxin results in impaired child growth: a longitudinal study in Benin, West Africa. Environmental Health Perspectives 112 1334-1338.
Hafez AH, Megalla SE \& Mahmed AA 1982 Aflatoxin and aflatoxicosis. III. Effect of dietary aflatoxin on the morphology of buffalo bull spermatozoa. Mycopathologia 77 141-144.

Handelsman DJ 2001 Estrogens and falling sperm counts. Reproduction, Fertility, and Development 13 317-324.

Hayat MA 1981 The production of artifacts. Ultrastructural Pathology 293.

Herath CB, Jin W, Watanabe G, Arai K, Suzuki AK \& Taya K 2004 Adverse effects of environmental toxicants, octylphenol and bisphenol A, on male reproductive functions in pubertal rats. Endocrine 25 163-172.

Hess RA 1990 Quantitative and qualitative characteristics of the stages and transitions in the cycle of the rat seminiferous epithelium: light microscopic observations of perfusion-fixed and plastic-embedded testes. Biology of Reproduction 43 525-542.

Hess RA \& Thurston RJ 1977 Ultrastructure of epithelial cells in the epididymal region of the Turkey (Meleagris gallopavo). Journal of Anatomy 124 765-778.

Hoffer AP 1982 Ultrastuctural studies of spermatozoa and the epithelial lining of the epididymis and vas deferens in rats treated with gossypol. Archives of Andrology 8 233-246.

Holschbach C \& Cooper TGA 2002 A possible extratubular origin of epididymal basal cells in mice. Reproduction 123 517-525.

Ibeh IN \& Saxena DK 1998 Effect of alpha-tocopherol supplementation on the impact of aflatoxin B1 on the testes of rats. Experimental and Toxicologic Pathology 50 221-224.

Ibeh IN, Uraih N \& Ogonar JL 1994 Dietary exposure to aflatoxin in human male infertility in Benin City, Nigeria. International Journal of Fertility and Menopausal Studies 39 208-214.

Ihara M, Kinoshita A, Yamada S, Tanaka H, Tanigaki A, Goto M, Okubo K, Nishiyama $\mathrm{H}$, Ogawa $\mathrm{O}$, Takahashi C, Itohara S, Nishimune $\mathrm{Y}$, Noda $M$ \& Kinoshita M 2005 Cortical organization by the septin cytoskeleton is essential for structural and mechanical integrity of mammalian spermatozoa. Developmental Cell 8 343-352.

lida H, Honda Y, Matsuyama T, Shibata Y \& Inai T 2006 Tektin 4 is located on outer dense fibres, not associated with axonemal tubulins of flagella in rodent spermatozoa. Molecular Reproduction and Development $\mathbf{7 3}$ 929-936.

Inaba K 2003 Molecular architecture of the sperm flagella: molecules for motility and signalling. Zoological Science 20 1043-1056.

Irons MJ 1983 Synthesis and assembly of connecting-piece proteins as revealed by radioautography. Journal of Ultrastructure Research 82 27-34.

Ishijima S, Iwamoto T, Nozawa S \& Matsushita K 2002 Motor apparatus in human spermatozoa that lack central pair microtubule. Molecular Reproduction and Development 63 459-463.

Kalorey DR, Daginawala HF, Ganorkar AG \& Mangle N 1996 Serum zinc and iron status in experimental aflatoxicosis in chicks. Indian Journal of Veterinary Research 5 28-32.

Kann ML, Pradel LA \& Fouguet JP 1993 Spectrin and ankyrin like proteins in spermatids and spermatozoa of the hamster and some other mammals. Reproduction, Nutrition, Development 33 51-61.

Kann MI, Prigent Y, Levilliers N, Bré MH \& Fouguet JP 1998 Expression of glycylated tubulin during the differentiation of spermatozoa in mammals. Cell Motility and the Cytoskeleton 41 341-352.

Kanous KS, Casey C \& Lindemann CB 1993 Inhibition of microtubule sliding by $\mathrm{Ni}^{2+}$ and $\mathrm{Cd}^{2+}$ : evidence for a differential response of certain microtubule pairs within the bovine sperm axoneme. Cell Motility and the Cytoskeleton 26 66-76.

Karnovsky MJ 1965 A formaldehyde-glutaraldehyde fixative of high osmolarity for use in electron microscopy. Journal of Cell Biology $25137 \mathrm{~A}$.

Kinukawa M, Nagata M \& Aoki F 2004 Reducing agents induce microtubule extrution in demembranated mammalian spermatozoa. Reproduction 128 813-818.

Koo EW, Haves MA, Wong MK \& Gotlieb Al 1987 Aflatoxin B1 and acetaminophen induce different cytoskeletal responses during prelethal hepatocytes injury. Experimental and Molecular Pathology 47 37-47.

Le Lannou D \& Blanchard Y 1988 Nuclear maturity and morphology of human spermatozoa selected by Percoll density gradient centrifugation or swim-up procedure. Journal of Reproduction and Fertility 84 551-556.

Mocchegiani E, Corradi A, Santarelli L, Tibaldi A, DeAngelis E, Borghetti P, Bonomi A, Fabris N \& Cabassi E 1996 Zinc, thymic endocrine activity and mitogens responsiveness (PHA) in piglets exposed to maternal aflatoxicosis B1 and G1. Veterinary Immunology and Immunopathology 16 245-260. 
Mortimer D \& Mortimer ST 2005 Laboratory investigation of the infertile male. In Textbook of In Vitro Fertilization and Assisted Reproduction, edn 3, pp 61-91. Ed. PR Brinsden. London and New York: Taylor \& Francis.

Oko R \& Hrudka F 1982 Segmental aplasia of the mitochondrial sheath and sequelae induced by gossypol in rat spermatozoa. Biology of Reproduction 26 183-195.

Olson GE \& Linck RW 1977 Observations of the structural components of flagellar axonemes and central pair microtubules from rat sperm. Journal of Ultrastructure Research 61 21-43.

Olson GE, Winfrey VP, Hill KE \& Burk RF 2004 Sequential development of flagellar defects in spermatids and epididymal spermatozoa of seleniumdeficient rats. Reproduction 127 335-342.

Olson GE, Winfrey VP, Nagdas SK, Hill KE \& Burk RF 2005 Selenoprotein P is required for mouse sperm development. Biology of Reproduction 73 201-211.

Paranko J, Yagi A \& Kuusisto M 1994 Immunocytochemical detection of actin and $53 \mathrm{kDa}$ polypeptide in the epididymal spermatozoa of rat and mouse. Anatomical Record 240 516-527.

Peters LP \& Teel RW 2003 Effect of high sucrose diet on liver enzyme content and activity and aflatoxin B1-induced mutagenesis. In Vivo 17 205-210.

Picha J, Cerovský J \& Pichová D 1986 Fluctuation in the concentration of sex steroids and aflatoxin B1 in the seminal plasma of boars and its relation to sperm production. Veterinární medicína 31 347-357.

Preston RJ \& Williams GM 2005 DNA-reactive carcinogens: mode of action and human cancer hazard. Critical Reviews in Toxicology 35 673-683.

Roy A, Lin YN, Agno JE, DeMayo FJ \& Matzuk MM 2007 Absence of tektin 4 causes asthenozoospermia and subfertility in male mice. FASEB Journal 21 1013-1025.

Schalles U, Shao X, van der Hoorn FA \& Oko R 1998 Developmental expression of the $84-\mathrm{kDa}$ ODF sperm protein: localization to both the cortex and medulla of outer dense fibres and to the connecting piece. Developmental Biology 199 250-260.

Seiler P, Cooper TG \& Nieschlag E 2000 Sperm number and condition affect the number of basal cells and their expression of macrophage antigen in the murine epididymis. International Journal of Andrology 23 65-76.

Sharlin JS, Howarth B Jr \& Wyatt RD 1980 Effect of dietary aflatoxin on reproductive performance of mature White Leghorn males. Poultry Science 59 1311-1315.

Sharpe RM 1992 Are environmental chemicals a threat to male fertility? Chemistry and Industry 3 88-94.

Sharpe RM 2006 Pathways of endocrine disruption during male sexual differentiation and masculanization, Best Practice \& Research. Clinics in Endocrinology and Metabolism 20 91-110.

Sharpe RM \& Skakkebaek NE 1993 Are estrogens involved in falling sperm counts and disorders of the male reproductive tract? Lancet 341 1392-1395.

Shephard GS 2003 Aflatoxin and food safety: recent African perspectives. Journal of Toxicology and Environmental Health 22 267-286.

Si Y \& Okuno M 1993 The sliding of the fibrous sheath through the axoneme proximally together with microtubule extrusion. Experimental Cell Research 208 170-174.

Si Y \& Okuno M 1995 Extrusion of microtubule doublet outer dense fibres 5-6 associating with fibrous sheath sliding in mouse sperm flagella. Journal of Experimental Zoology 273 355-362.

Sivashanmugam P \& Rajalakshmi M 1997 Sperm maturation in rhesus monkey: changes in ultrastrucuture, chromatin condensation, and organization of lipid bilayer. Anatomical Record 247 25-32.

Skakkebaek NE, Rajpert-De Meyts E, Jorgensen N, Carlsen E, Petersen PM, Giwercman A, Andersen AG, Jensen TK, Andersson AM \& Muller J 1998 Germ cell cancer and disorders of spermatogenesis: an environmental connection? APMIS 3-11 12.

Slama R, Jegou B \& Cordier S 2006 Breakthroughs in the study of the influence of environmental factors on male reproductive health. Revue d'Épidémiologie et de Santé Publique 54 167-174.

Sotomayor RE, Sahu S, Washington M, Hinton DM \& Chou M 1999 Temporal patterns of DNA adduct formation and glutathione transferase activity in the testes of rats fed with aflatoxin B1: a comparison with patterns in the liver. Environmental and Molecular Mutagenesisue 33 293-302.

Spector DL, Goldman RD \& Leinwand LA 1997 In Cells: A Laboratory Manual. Culture and Biochemical Analysis of Cells, vol 1, pp 15.6-15.7. USA: Cold Spring Harbor Laboratory Press.

Strosnider H, Azziz-Baumgartner E, Banziger M, Bhat RV, Breiman R, Brune MN, DeCock K, Dilley A, Groopman J, Hell K et al. 2006 Workshop Report: public health strategies for reducing exposure in developing countries. Environmental Health Perspectives 114 1898-1903.

Sutovsky P, Moreno R, Ramalho-Santos J, Dominko T \& Thompson WE 2001a A putative, ubiquitin-dependent mechanism for the recognition and elimination of defective spermatozoa in the mammalian epididymis. Journal of Cell Science 114 1665-1675.

Sutovsky P, Terada Y \& Schatten G $2001 b$ Ubiquitin-based sperm assay for the diagnosis of male factor infertility. Human Reproduction 16 250-258.

Swan MA, Vishwanath R, White IG \& Brown-Woodman PD 1990 Electron microscopic observations on the effect of gossypol on rat cauda epididymis. Zeitschrift für physiologische Chemie 104 273-286.

Touré A, Lhuillier P, Gossen JA, Kuil CW, Lhôte D, Jégou B, Escalier D \& Gacon G 2007 The testis anion transporter 1 (Sic26a8) is required for sperm terminal differentiation and male fertility in the mouse. Human Molecular Genetics 16 1783-1793.

Tso WW \& Lee CS 1982 Gossypol uncoupling of respiratory chain and oxidative phosphorylation in ejaculated boar spermatozoa. Contraception 25 649-655.

Turner PC, Moore SE, Hall AJ, Prentice AM \& Wild CP 2003 Modification of immune function through exposure to dietary aflatoxin in Gambian children. Environmental Health Perspectives 111 217-220.

Uriah N, Ibeh IN \& Oluwafemi F 2001 A Study on the Impact of Aflatoxin on Human Reproduction. African Journal of Reproductive Health 5 106-110.

Vaid KS, Guttman JA, Babyak N, Deng W, McNiven MA, Mochizuki N, Finlay BB \& Vogl AW 2007 The role of dyamin 3 in the testis. Journal of Celluar Physiology 210 644-654.

Veeramachaneni DN 2000 Deteriorating trends in male reproduction: idiopathic or environmental? Animal Reproduction Science 60-61 121-130.

Wang JS \& Groopman JD 1999 DNA damage by mycotoxins. Mutation Research 424 167-181.

Williams JH, Phillips TD, Jolly PE, Stiles JK, Jolly CM \& Aggarwal D 2004 Human aflatoxicosis in developing countries; a review of toxicology, exposure, potential health consequences, and interventions. American Journal of Clinical Nutrition B 80 1106-1122.

Winters SJ, Wang C, Abdelrahaman E, Hadeed V, Dyky MA \& Brufsky A 2006 Inhibin-B levels in healthy young adult men and prepubertal boys: is obesity the cause for the contemporary decline in sperm count because of fewer Sertoli cells? Journal of Andrology 27 560-564.

Wirth PJ 1994 Two-dimensional polyacrylamide gel electrophoresis in experimental hepatocarcinogenesis studies. Electrophoresis 15 354-371.

Xiao X \& Yang WX 2007 Actin-based dynamics during spermatogenesis and its significance. Journal of Zhejiang University. Science B8 498-506.

Xue SP, Liang DC, Fei RR, Chen XM, Ye SJ, Liu Y, Wu YW, You MM \& Guo XY 1983 Subcellular site of antispermatogenic effect of gossypol and its possible molecular mechanism of action. Scientia Sinica 26 614-633.

Yanagimachi R 2005 Male gamete contributions to the embryo. Annals of the New York Academy of Science 1061 203-207.

Received 7 August 2007

First decision 7 September 2007

Revised manuscript received 1 November 2007

Accepted 4 December 2007 